\title{
Farklı Mevsimlerde Uygulanan Değişik Aydınlatma Programlarının Broiler Performansına Etkileri
}

\author{
Okan ELIBOL'
}

\author{
Sedat AKTAN ${ }^{2}$
}

Geliş Tarihi: 28.12 .2001

\author{
Mesut TÜRKOĞLU'
}

\begin{abstract}
Özet: Bu araştırmada, perdeli kümeslerde, doğal ve sürekli aydınlatma programlarının üretim döneminde dönüşümlü olarak uygulanmasının, broiler performansı üzerine etkilerinin iki farklı mevsimde belirlenmesi amaçlanmıştır. Araştırmada 1. mevsim olarak temmuz-ağustos (yaz), ikinci mevsim olarak da ekim-kasım (sonbahar) ayları seçilmiştir. Her iki mevsimde de ilk 7 gün sürekli aydınlatma uygulanmıştır. Her mevsim için 4 farklı grup oluşturulmuş ve bunlardan ilkine 7-42, günler arasında sürekli aydınlatma yapılmış, ikincisi yalnızca doğal gün uzunluğuna tabii tutulmuştur. Üçüncü gruba 8-21. günler, 4. gruba da 22-42. günler arası 23 saat aydınlatma uygulanmış, diğer dönemlerde gün ışığı ile yetinilmiştir. Birinci mevsimde, sürekli ve/veya 22. günden sonra sürekli aydınlatma daha iyi sonuç verirken, sonbahar mevsiminde aydınlatma grupları arasinda önemli bir fark tespit edilmemiştir. Bu durum, birinci mevsimde (yaz) üretim döneminin tamamında ya da 22-42. günler arası sürekli aydınlatmanın, hayvanlara sıcaklığın düştüğü zamanlarda (gece) yem tüketme şansı vermesinin etkisi olarak anlaşılmaktadır. Sonuç olarak broilerlerde uygulanacak aydınlatma programına mevsimin de dikkate alınarak karar verilmesinin daha doğru olacağı söylenebilir.
\end{abstract}

Anahtar Kelimeler: broiler, aydınlatma, performans

\section{Effects of Different Lighting Regimes in Different Seasons on Broiler Performance}

\begin{abstract}
This study was conducted to determine the restricted light in curtain-sided poultry houses on broiler performances in two different seasons. The first trial was conducted in july-august (summer) and the second trial was undertaken in october- november (fall). In the first 7 days, lighting schedules was $23 \mathrm{~h}$ light in all groups. Groups were constituted as follows: continuous lighting between 7 to 42 days (1), natural day length between 7 to 42 days (2), continuous lighting between 7 to 21 days, following natural day length up to 42 days (3) and natural day length between 7 to 21 days, following continuous lighting up to 42 days (4). It was observed that best results were obtained from group 1 and 4 in Trial 1, but there were no statistically significant differences between groups in Trial 2. As a results of these experimental findings, it is concluded that it is detrimental effect to use a restricted lighting schedule in Summer time as high temperature may prevent to feed consumption however it is possible to use a restricted lighting schedule in Fall.
\end{abstract}

Key Words: broiler, lighting, performance

\section{Giriş}

Son yıllarda ıslah firmaları, pazar istekleri doğrultusunda, broiler üretiminde seleksiyon kriteri olarak yemden yararlanma, büyüme hızı ve karkas randımanı gibi özelliklere daha fazla ağırlık vermektedirler. Ancak büyüme hızı ve yem değerlendirme özelliklerinde elde edilen olumlu gelişmeler yanında, karın içi yağ oranının artması, ayak problemlerinin çoğalması, ascites (karında su toplama) gibi sorunlar da artmaya başlamıştır. Broiler üretiminde görülen bu olumsuzlukların giderilmesi için değişik uygulamalara başvurulmaktadır. Bunlardan birisi de, genel olarak 23 saat aydınlık ve 1 saat karanlık şeklinde yapılan klasik aydınlatma programı yerine, alternatif aydınlatma programları uygulamaktır. Alternatif aydınlatma programlarında temel amaç, yukarıda belirtilen olumsuzluklari ortadan kaldırmak için erken yaşlarda büyüme hızını yavaşlatarak ölüm oranını düşürmek, yemden yararlanma ve toplam canlı ağırlık artışını artırmaktır.

\footnotetext{
${ }^{1}$ Ankara Üniv. Ziraat Fak. Zootekni Bölümü-Ankara

${ }^{2}$ Süleyman Demirel Üniv. Ziraat Fak. Zootekni Bölümü-Isparta
}

Carter (1967), Beane ve ark. (1979) optimum büyüme ve yem değerlendirme için sürekli aydınlatmanın gerekli olduğunu belirtirken, Thyagarajan ve ark. (1987) uzun süreli aydınlatmanın canlı ağırlık üzerinde olumlu etkisi olmasına karşılık, yem değerlendirme ve yaşama gücüne önemli bir etkisinin olmadığını bildirmişlerdir. Bunun yanında sürekli ve daha kısa aydınlatma süreleri uygulanarak büyütülen broilerlerde performans bakımından önemli bir farkın olmadığı da birçok araştırıcı tarafından bildirilmektedir (Thomsen 1994, Renden ve ark. 1996, Azman ve ark. 1997, Zulkifli ve Norma 1997).

Carrasco ve ark. (1986) sıcak havalarda doğal aydınlatmaya göre gece saatlerinde 8 saat süreyle uygulanan ilave aydınlatmanın canlı ağırlık ve yemden yararlanma üzerinde önemli seviyede etkili olduğunu bildirmişlerdir. Donkoh ve ark. (1989) sürekli aydınlat-ma uygulanan broilerlerin gündüz veya gece 12 'şer saat 
süreyle aydınlatma uygulanan broilerlere göre daha kötü yem değerlendirmeye sahip olduklarını, buna karşılık aydınlatma süresinin yaşama gücü üzerinde herhangi bir etkisinin olmadığını saptamışlardır. Classen ve Riddell (1989) 0-21 günlük büyüme döneminde aydınlatma süresini 6 saate indirip, daha sonra kademeli olarak veya aniden 23 saate çıkarmanın, 23 saat sürekli uygulanan aydinlatmaya göre ölüm oranı ve ayak bacak problemlerinde önemli azalmalar sağladığını bildirmiştir. Aynı araştırıcı, aydınlatma süresi kademeli olarak artırılan gruplar ile sürekli aydınlatmaya maruz bırakılan gruplar arasında kesim ağırlıkları bakımından önemli bir fark olmadığını ve birincisinde yemden yararlanmanın daha iyi olduğunu belirtmiştir. Illk üç hafta sınırlı aydınlatma uygulanan gruplarda gelişme geriliği görülmediğini, kesim yaşına kadar 12 saat aydınlık, 12 saat karanlık veya 14 saat aydınlık, 10 saat karanlık uygulanan gruplarda 42 . güne kadar görülen gelişme geriliğinin kesim yaşı 49 güne uzatıldığında telafi edildiğini saptamışlardır. Ayrıca aydinlatma grupları arasında yemden yararlanma, karkas özellikleri ve karın içi yağı bakımından önemli bir fark olmadığını bildirmişlerdir.

Aydınlatma süresinin broilerlerde canlı ağırlık, yemden yararlanma ve ölüm oranı gibi önemli verim özellikleri üzerine etkilerinin dönemden döneme farklı olup olmadığını ortaya koymak için yürütülen ve kesim yașı 7 hafta olan bir başka araştırma sonucunda, beşinci haftaya kadar doğal, son iki haftada ise toplam 23 saatlik aydınlatmanın, canlı ağırlık artışı üzerine sürekli aydınlatmadan daha olumlu etkide bulunduğu tespit edilmiştir (Stanley ve ark. 1997). Altan ve ark. (1998) perdeli kümeslerde 3. günden sonra sınırlı aydınlatma uygulayarak etlik piliç performansında önemli bir gerileme olmaksızın büyütme yapılabileceg̃ini bildirmişlerdir. Ișcan (1999) yapmış olduğu çalışmada çevre kontrollü kümes bölmelerinde sürekli aydınlatma yanında Türkiye'de farklı mevsimlerde gözlenebilen 3 değişik gün uzunluğu ile bu sürelerin her birinde 3 farklı gece aydınlatma programlarını karşılaştırmıştır. Kış mevsiminde karanlık dönemde 1 saat aydınlik, 3 saat karanlık, bahar ve yaz aylarında ise 1 saat aydınlık, 1 saat karanlık kesikli gece aydınlatma programlarınin broiler performansi üzerine sürekli aydınlatmaya göre daha olumlu etkide bulunduğunu belirtmiştir.

Alternatif aydınlatma programları genel olarak 2 farklı uygulama grubunda toplanabilir. Bunlardan birincisi, kesikli aydınlatma olup çevre kontrollü kümeslerde daha etkin olarak kullanımakla birlikte perdeli kümeslerde ancak karanlık dönemde yaprlabilmektedir. Ikinci uygulama ise sınırlı aydınlatma programlarıdır. Özellikle 21 günden sonra aydınlatma süresinin artırıldığı bu program, perdeli kümeslerin yoğun olduğu Türkiye'de daha kolay uygulanabilir.

Bu araştırmada da iki farklı mevsimde, perdeli kümeslerde, doğal ve sürekli aydinlatma ile bu iki uygulamanın üretim dönemi içerisinde dönüșümlä olarak kullanılmasının, yani sınırlı aydınlatma programlarının broiler performansı üzerine olan etkilerinin belirlenmesi amaçlanmıştır.

\section{Materyal ve Yöntem}

Araştırma Ankara Universitesi Ziraat Fakültesi Araştırma ve Uygulama Çiftliği broiler kümesinde yürütülmüștür. Araştırma aynı kümeste yaz (temmuzağustos) ve sonbahar (ekim-kasım) olmak üzere iki farklı dönemde tekrarlanmıştır. Havalandırması doğal yolla sağlanan, (perdeli) broiler kümesi, her birinde yaklaşık 10 $\mathrm{m}^{2}$ lik 8 bölme bulunan 4 ayrı odadan oluşmaktadır. Söz konusu 32 bölmenin iki odadaki 16 tanesi araştırmaya ayrılmıştır. Bölme bazında yem tüketiminin hesaplanabilmesi için kovalı yemlikler kullanılmış, isıtma ise likid gaz ile çalışan radyanlarla sağlanmıştır.

Yetiştirme süresinde 4 farklı dönemde nitelikleri Çizelge $1^{\prime}$ de verilen ( $0-15,16-25,26-35$ ve $36-42$. günler için) 4 değişik rasyon kullanılmıştır. Söz konusu rasyonlar araștırma uygulama çiftliğinde yem ünitesinde hazırlanmıștır.

7. güne kadar 23 saat sürekli aydınlatma uygulanan ve bir arada tutulan civcivler 8 . günde iki odada bulunan toplam 16 bölmeye, her bölmede 150 hayvan olacak şekilde yerleştirilmişlerdir. Her iki denemede de aydınlatma gruplan aşağıdaki gibi oluşturulmuştur (Çizelge 2).

Odalardan birisinde doğal gün uzunluğu, diğerinde ise 23 saat sürekli aydınlatma uygulanmıştır. 21. günün sonunda doğal gün uzunluğuna maruz bırakılan 3 . gruptaki hayvanlar ile 23 saat sürekli aydınlatmanın uygulandığı 4. gruptaki hayvanların yerleri değiştirilmiştir. Buna göre birinci gruptaki hayvanlara (1) kesime kadar (42. gün) sürekli aydınlatma, ikinci gruptaki hayvanlara (2) kesime kadar yalnızca doğal aydınlatma, üçüncü gruptaki hayvanlara (3) 21. güne kadar sürekli ve sonrasinda kesime kadar doğal aydınlatma, dördüncü gruptaki hayvanlara (4) ise 21 . güne kadar doğal ve sonrasında kesime kadar sürekli aydınlatma uygulanmıştır.

Deneme süresince $7 ., 21$, ve 42 . günlerde yaklaşık $10^{\prime}$ ar hayvanlık gruplar halinde bütün bireyler tartılmıștır. Ölen ve ayıklanan hayvanlara ait bilgiler günlük olarak kaydedilmiştir. Verilen yem miktarları günlük olarak kartlara işlenmiş, tartım dönemlerinde artan yem miktarları belirlenerek yem değerlendirmeye ilişkin veriler elde edilmiştir.

Üzerinde durulan özellikler bakımından gruplar arası farklılıkların belirlenmesinde varyans analizi tekniği, farklılığı yaratan grupların belirlenmesinde Duncan testi, ölüm oranlarının değerlendirilmesinde ise Khi kare analizi kullanılmıştır (Düzgüneş ve ark. 1987). Adı geçen istatistik analizler Minitab ve MSTAT-C isimli bilgisayar paket programları ile yapıimıştır.

\section{Bulgular ve Tartışma}

Her iki denemede de beklendiği üzere denemenin başlangıcı olan 7. gün canlı ağırlıkları bakımından gruplar arasında fark tespit edilmemiştir (Çizelge 3). Birinci denemede, 2 . ve 4 . gruplarda 21. gün canlı ağırlığı 
Çizelge 1. Değişik dönemlerde kullanilan rasyonlanın ham protein ve enerji düzeyleri*

\begin{tabular}{|c|c|c|}
\hline Dönem (gün) & $\begin{array}{c}\text { Ham protein } \\
(\mathrm{g} / 100 \mathrm{~g})\end{array}$ & $\begin{array}{c}\text { Enerji } \\
\text { (kcal/ME) }\end{array}$ \\
\hline $0-15$ & 20.50 & 3100 \\
$16-25$ & 18.00 & 3175 \\
$26-35$ & 18.00 & 3225 \\
$36-42$ & 19.00 & 3275 \\
\hline
\end{tabular}

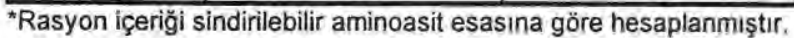

Çizelge 2. Denemelerde uygulanan aydınlatma programları

\begin{tabular}{|c|c|c|}
\hline & $7-21$ gün & $22-42$ gün \\
\hline Grup 1 & SA & SA \\
\hline Grup 2 & DA & DA \\
\hline Grup 3 & SA & DA \\
\hline Grup 4 & DA & SA \\
\hline
\end{tabular}

SA: sürekli aydınlatma

DA: doğal aydinlatma

diğerlerinden önemli seviyede düşük bulunmuştur $(P<0.01)$. Buna karşın deneme sonu olan 42 . gün ağırlığı bakımından 1, ve 4, gruplara ait ortalama değerler, diğer 2 gruptan önemli seviyede yüksek bulunmuştur. Yaz dönemindeki 4 grubun ortalama canlı ağırlığı sırasıyla 1921.6, 1780.7, 1763.1 ve 1866.8 g olarak hesaplanmıştır. Grupların, 21. gün canlı ağırlıklarına bakıldığında 7-21. gün arasında doğal aydınlatmaya maruz bırakılan 2 ve 4 grubun canlı ağırıklarının düşük olduğu görülmektedir. Ancak 21-42 günler arasında 23 saat sürekli aydınlatma uygulanan 4 . grubun, gelişme geriliğini telafi edebildiği anlaşılmaktadır. Sonbahar döneminde ise yaz döneminin aksine bütün gruplarda ve her dönemde canlı ağırlıklar arasındaki fark istatistiksel olarak önemli bulunmamıştır ( $P>0.05)$.

Yaz ve sonbaharda yürütülen denemelerde; gruplara ait yem değerlendirme sayıları Çizelge 4'de verilmiştir. Çizelge 4'den de görüleceği gibi yalnızca yazın yürütülen deneme de 22-42. günler arasında yem değerlendirme sayısı bakımından 3. grup ile 1. ve 4. gruplar arasında fark önemli bulunmuştur $(P<0.05)$. Sonbaharda yürütülen denemede ise yem değerlendirme sayısı bakımından ilgili dönemlerin hepsinde gruplar arası farkın önemsiz olduğu saptanmıştır $(P>0,05)$. Bu durum da Thyagarajan ve ark. (1987), Thomsen (1994), Renden ve ark. (1996), Zulkifli ve Norma (1997) ile Altan ve ark. (1998)'in bildirişleriyle uyum halindedir

Her iki dönemde (yaz, sonbahar) de. farklı aydınlatma programlarının ölüm oranı bakımından bir farklııı yaratmadığı tespit edilmiştir. Bu durum Thyagarajan ve ark. (1987), Donkoh ve ark. (1989), Renden ve ark. (1996) ve Altan ve ark. (1998)'in bildirişleriyle uyum göstermektedir.

Yaz ve sonbaharda yürütülen denemelerde canlı ağırlıklar bakımından aydınlatma programları arasındaki farkın aynı olmaması mevsim $x$ aydınlatma programı interaksiyonunu akla getirmektedir. Yaz mevsiminde yetiştirme periyodunun tamamında ya da son yarısında doğal aydınlatma uygulanan grupların 42 , gün, sadece 7 21. günler arasında doğal aydınlatma uygulanan grubunda 21. gün ağırığının düşük olması, buna karşilık sonbahar mevsiminde bir farklılık görülmemesi aydınlatma süresinden başka faktörlerin üzerinde durulması gerektiğine işaret etmektedir. Bu unsurlar içerisinde ilk akla gelen kümes sıcaklığıdır. Her ne kadar söz konusu kümeste kümes içi sıcaklığı ölçülmemiş ise de, dış sıcaklığın iç sıcaklığı etkilediği bilinmektedir. Bu konuda bir fikir yürütebilmek için Çizelge $5^{\prime}$ deki verilere bir göz atmak yararlı olacaktır.

Sıcaklıkların yüksek olduğu dönemde suni aydınlatma ile hayvanların gece saatlerinde de beslenebilmelerine olanak sağlayan aydınlatma programlariyla elde edilen avantaj Carrasco ve ark. (1986), Thyagarajan ve ark. (1987), Donkoh ve ark. (1989) ile Zulkifli ve Norma (1997)'nin bildirişleriyle uyum göstermiştir. Buna karşilik sonbaharda yürütülen deneme sonucunda gruplar arasında farklılık olmaması şeklinde ortaya çikan durum ise Thomsen (1994), Renden ve ark. (1996), Zulkifli ve Norma (1997), Altan ve ark. (1998)'in bildirişleriyle uyumludur. Türkiye'de mevsimlere göre uygun aydınlatma programlarını belirlemeye çalışan Işcan (1999) mevsimin etkisini sadece gün uzunluğu olarak değerlendirmiş, mevsime bağlı diğer unsurları özellikle de sıcaklığın etkisini göz ardı etmiştir.

Bilindiği üzere broiler üretiminde amaç, kısa süre içinde hayvanların canlı ağırlıklarının artırılmasıdır. Ağırlık artişıyla yem tüketimi ilişkisi göz önünde tutularak bireylere sürekli yem tüketme imkanı yaratmaya çalışılır. Bunun için de sürekli aydınlık bir ortam oluşturul-maktadır. Ancak Gore ve ark. (1969) broilerler için günlük yem yeme süresinin 3.6 saat olarak tespit ederken, Weaver ve Siegel (1968) yem yeme süresinin uzaması durumunda yem değerlendirmenin iyileşmediğini bildir-miştir. Bu durum da broiler üretiminde aydınlık sürenin artmasının performans üzerine önemli bir etkisinin olmayacağı söylenebilir. Bu araştırmada da, özellikle sonbaharda yürütülen denemede, doğal gün uzunluğunun 12 saatin altına düşmesinin, aydınlatmaya tabii tutulan grupla sürekli aydınlatma yapılan grupların performans değerleri arasındaki farkı etkilemediği tespit edilmiştir.

\section{Sonuç}

Doğal gũn uzunluğu veya sürekli aydınlatma ya da bunların dönüşümlü olarak uygulanması, broilerlerde performans üzerinde mevsime bağlı olarak farklı etki göstermiştir. Araştırma sonucunda sıcaklığın daha yüksek olduğu Yaz döneminde geceleri de beslenmeye olanak veren sürekli ve/veya 22 . günden sonra sürekli aydınlatmanın daha iyi sonuç vermiş, gündüz sıcaklıklarının yem tüketimini olumsuz yönde etkilemediği düşünülen sonbahar döneminde ise performans değerleri bakımından gruplar arasında önemli bir fark tespit edilmemiştir. Buna göre broilerler de uygulanacak aydınlatma programına cinsiyet, hedeflenen kesim ağırlığı, kümes tipi gibi faktörlerin yanında, mevsimin de dikkate alınarak karar verilmesinin daha doğru olacağı söylenebilir. 
ELIBOL, O., S. AKTAN ve M. TÜRKOGLU, "Farklı mevsimlerde uygulanan değişik aydınlatma programlarının broiler performansına etkileri"

Çizelge 3. Her iki denemede ilgili dönemlerde belirlenen canlı ağırlıklar $\left(\bar{X} \pm S_{\bar{X}} g\right)$

\begin{tabular}{|c|c|c|c|c|c|c|c|c|}
\hline \multirow{2}{*}{$\begin{array}{c}\text { Dönem } \\
\text { (gün) }\end{array}$} & \multicolumn{4}{|c|}{ Deneme $1^{\star}$ (yaz) } & \multicolumn{4}{c|}{ Deneme 2 (sonbahar) } \\
\cline { 2 - 8 } & Grup 1 & Grup 2 & Grup 3 & Grup 4 & Grup 1 & Grup 2 & Grup 3 & Grup 4 \\
\hline 7 & $\begin{array}{c}125.04 \pm 1 \\
12\end{array}$ & $130.06 \pm 1.79$ & $131.13 \pm 1.76$ & $128.31 \pm 1.99$ & $118.73 \pm 0.50$ & $117.10 \pm 0.72$ & $117.58 \pm 0.83$ & $116.58 \pm 0.54$ \\
\hline 21 & $\begin{array}{c}691.43 \pm 7 . \\
88^{\mathrm{a}}\end{array}$ & $645.67 \pm 7.59^{\mathrm{b}}$ & $685.05 \pm 7.99^{\mathrm{a}}$ & $628.92 \pm 5.62^{\mathrm{b}}$ & $625.83 \pm 8.32$ & $598.30 \pm 7.42$ & $611.89 \pm 9.81$ & $621.40 \pm 6.98$ \\
\hline 42 & $\begin{array}{c}1921.6 \pm 2 \\
6.4^{\mathrm{a}}\end{array}$ & $1780.7 \pm 27.7^{\mathrm{b}}$ & $1763.1 \pm 15.8^{\mathrm{b}}$ & $1866.8 \pm 20.6^{\mathrm{a}}$ & $1835.7 \pm 21.4$ & $1899.6 \pm 27.0$ & $1853.1 \pm 36.4$ & $1818.3 \pm 23.2$ \\
\hline
\end{tabular}

* Deneme 1'de ilgili dönemlerde aynı satırda farkı harf taşıyan grup ortalamaları arasındaki farklar $\mathrm{P}<0.01$ düzeyinde önemlidir.

Çizelge 4. Her iki denemede ilgili dönemlerde belirlenen yem değerlendirme sayısı $\left(\bar{X} \pm S_{\bar{X}}\right)$

\begin{tabular}{|c|c|c|c|c|c|c|c|c|}
\hline \multirow{2}{*}{$\begin{array}{c}\text { Dönem } \\
\text { (gün) }\end{array}$} & \multicolumn{4}{|c|}{ Deneme 1* } & \multicolumn{4}{c|}{ Deneme 2 } \\
\cline { 2 - 9 } & Grup 1 & Grup 2 & Grup 3 & Grup 4 & Grup 1 & Grup 2 & Grup 3 & Grup 4 \\
\hline $7-21$ & $1.72 \pm 0.04$ & $1.76 \pm 0.03$ & $1.79 \pm 0.05$ & $1.80 \pm 0.06$ & $1.71 \pm 0.02$ & $1.74 \pm 0.03$ & $1.75 \pm 0.03$ & $1.75 \pm 0.02$ \\
\hline $22-42$ & $2.34 \pm 0.09^{\mathrm{b}}$ & $2.38 \pm 0.09^{\mathrm{ab}}$ & $2.55 \pm 0.01^{\mathrm{a}}$ & $2.18 \pm 0.04^{\mathrm{b}}$ & $2.43 \pm 0.06$ & $2.48 \pm 0.06$ & $2.56 \pm 0.03$ & $2.50 \pm 0.05$ \\
\hline $7-42$ & $2.03 \pm 0.05$ & $2.07 \pm 0.04$ & $2.17 \pm 0.03$ & $1.99 \pm 0.05$ & $2.07 \pm 0.03$ & $2.11 \pm 0.03$ & $2.16 \pm 0.01$ & $2.13 \pm 0.03$ \\
\hline
\end{tabular}

* Deneme 1'de 22-42. günler arasında yem değerlendirme bakımından farklı harflerle gösterilen grup ortalamaları arasındaki farklılıklar $\mathrm{P}<0.05$ düzeyinde önemlidir.

Çizelge 5. Temmuz-ağustos (Deneme 1), ekim-kasım (Deneme 2) aylanı arasındaki ortalama çevre sıcakığı ve gün uzunluğuna ait bilgiler

\begin{tabular}{|c|c|c|c|c|c|c|c|c|c|c|c|c|c|c|}
\hline \multirow{4}{*}{ Hafta } & \multicolumn{7}{|c|}{ Deneme 1} & \multicolumn{7}{|c|}{ Deneme 2} \\
\hline & \multicolumn{6}{|c|}{ Sıcaklık değeri $\left({ }^{\circ} \mathrm{C}\right)$} & \multirow{3}{*}{$\begin{array}{l}\text { Gün } \\
\text { uzunluğu } \\
\text { (saat) }\end{array}$} & \multicolumn{6}{|c|}{ Sıcaklık değeri $\left({ }^{\circ} \mathrm{C}\right)$} & \multirow{3}{*}{$\begin{array}{c}\text { Gün uzunluğu } \\
\text { (saat) }\end{array}$} \\
\hline & \multicolumn{3}{|c|}{ Gündüz } & \multicolumn{3}{|c|}{ Gece } & & \multicolumn{3}{|c|}{ Gündüz } & \multicolumn{3}{|c|}{ Gece } & \\
\hline & Or. & Max. & Min. & Ort. & Max. & Min. & & Ort. & Max. & Min. & Ort. & Max. & Min. & \\
\hline 1 & 28,8 & 37,0 & 19,6 & 21,1 & 32,2 & 15,0 & 14,40 & 13,5 & 22,9 & 3,3 & 8,8 & 16,0 & 5,0 & 11,10 \\
\hline 2 & 29,1 & 40,8 & 12,8 & 21,5 & 35,8 & 12,3 & 14,30 & 9,6 & 16,8 & 3,3 & 5,1 & 10,4 & 2,4 & 11,00 \\
\hline 3 & 28,6 & 35,4 & 18,1 & 21,2 & 28,5 & 11,6 & 14,20 & 12,0 & 19,6 & 1,0 & 5,5 & 14,8 & 0,1 & 10,40 \\
\hline 4 & 28,6 & 32,5 & 20,0 & 22,0 & 28,3 & 17,0 & 14,10 & 15,3 & 20,8 & 4,4 & 7,9 & 13,2 & 0,5 & 10,20 \\
\hline 5 & 27,3 & 30,6 & 18,3 & 21,0 & 26,9 & 17,2 & 13,50 & 10,4 & 17,1 & $-1,0$ & 3,6 & 9,8 & $-1,8$ & 10,10 \\
\hline 6 & 28,3 & 31,2 & 16,7 & 19,8 & 26,5 & 16,4 & 13,40 & 9,3 & 15,4 & $-1,5$ & 2,7 & 7,5 & $-1,7$ & 10,00 \\
\hline
\end{tabular}

\section{Kaynaklar}

Altan, Ö., A. Altan ve S. Ozkan, 1998. Değişik aydınlatma yöntemlerinin etlik piliç performansı üzerine etkileri. Türk Veterinerlik ve Hayvancilık Dergisi, 22 (1) 97-103.

Azman, M. A., E. Başer, H. Tekik ve S. Yurtalan, 1997. Farklı aydınlatma programlarının broiler performansı üzerine etkileri. Hayvancilık Araştırma Dergisi, 7 (1) 1-4.

Beane, V. L., J. A. Cherry and W. D. Weaver, 1979. Intermittent light and restricted feeding of broiler chickens. Poultry Sci., $58,567-571$.

Carrasco, E., E. Perez, L. Fraga and I. Sevilla, 1986. Night photoperiod and supplemental lighting in broilers during the dry period. Cuban J. of Agric. Sci., 20 (3) 263-267.

Carter, T. C. 1967. Environmental Conrol in Poultry Production. Ed:Oliver and Boyd. Edinburg, London.
Classen, H. L. and C. Riddell, 1989. Photoperiodic effects on performance and leg abnormalities in broiler chicken. Poultry Sci., 68, 897.

Donkoh, A., C. Atuahene and A. G. Kese, 1989. Effect of feeding regimen and lighting pattern on the performance of broiler chickens in the hot, humid tropics. British Poultry Sci., 30 (2) $403-406$.

Düzgüneş, O., T. Kesici, O. Kavuncu ve F. Gürbüz, 1987. Istatistik Metotları II. Ankara Univ. Ziraat Fak. Yayınları: 1021, Ders Kitabı: 295. Ankara.

Gore, W. E., D. P Foshee and J. R. Howes, 1969. Effect of background illumination and light dark period on weight gain in broiler results. Poultry Digest.,1, 83.

Işcan, M. K. 1999. Farklı gün uzunluklarında uygulanan değişik kesikli aydınlatma programlarının broyler performansı üzerine etkileri. Türk Veterinerlik ve Hayvancılık Dergisi, 23. Ek sayı 4, 711-717. 
Renden, J. A., E. T. Moran and S. A.Kincaid, 1996. Lighting programs for broilers that reduce leg problems without loss of performance or yield. Poultry Sci., 75, 1345-1350.

Stanley, V. G., J.Gutierrez, A. L. Parks, S. A. Rhoden, H. Chukwu, C. Gray, and W. F. Krueger,1997. Relationship between age of commercial broiler chickens and response to photostimulation. Poultry Sci., 76, 306-310.

Thyagarajan, D., P. Kothandaraman, D. Narahari, A. Thangavel, V. Sundararasu and I. A. Jayaprasad, 1987. Effect of different lighting programmes on broilers' performance. Cheiron, 16 (6) 266-268.

Thomsen, M. G. 1994. Influence of stocking density and lighting systems on broiler performance and carcass quality. Proceedings, $9^{\text {th }}$ European Poultry Conference, Glasgow UK, 7-12 August 1994, Vol. 1, 137-138. I: Effects of different lighting treatment on broiler performance.

Weaver, W. D. and P. B. Siegel, 1968. Photoperiodism as a factor in feeding rhythm of broiler chicken. Poultry Sci., 47, 1148-1154.

Zulkifli, I. and M. T. Norma, 1997. Biological and economic performances of broiler chickens as affected by daylength and food location. J. Veterinary Malaysia, 9 (1) 1-6. 